\title{
Breve análise dos instrumentos da política de gestão ambiental brasileira
}

\author{
Dalmo Arantes Barros' \\ Luís Antônio Coimbra Borges ${ }^{2}$ \\ Gleisson de Oliveira Nascimento ${ }^{3}$ \\ José Aldo Alves Pereira ${ }^{4}$ \\ José Luiz Pereira de Rezendes \\ Rossi Alan Silva ${ }^{6}$
}

\section{Resumo}

O objetivo desse trabalho foi descrever os principais instrumentos da política ambiental brasileira, fazendo menção aos principais pontos de discussão do tema. Para isso, realizou-se uma pesquisa qualitativa do tipo exploratória. A principal falha da efetividade dos instrumentos da política do meio ambiente brasileiro está no desconhecimento quase total da política ambiental, de seus benefícios e de seus resultados, nos diferentes níveis de gestão. Para a eficácia da legislação ambiental, por meio da utilização dos instrumentos da Política Nacional do Meio Ambiente, é necessário mais do que só a normatização de vias de comando e controle. São imprescindíveis outras políticas públicas, como trabalhar junto à população na conscientização e divulgação de políticas educacionais com investimentos nos aspectos voltados para a sustentabilidade, mudança de hábitos de consumo e estilo de vida.

Palavras-chave: Instrumentos de gestão, política ambiental, efetividade.

I Doutorando em Engenharia Forestal, Universidade Federal de Lauras (UFLA), Lavras, Minas Gerais (MG), Brasil.dalmo.barros@posgrad.ufla.br

2 Doutor em Engenharia Florestal. Professor Adjunto, Universidade Federal de Lauras. luis.borges@dcf.ufla.br

3 Mestrando em Engenharia Florestal, Universidade Federal de Lauras. gleisson_czac@yahoo.com.br

4 Doutor em Ecologia (Conservação e Manejo da Vida Silvestre) pela Universidade Federal de Minas Gerais (UFMG), Brasil. Professor Associado, Universidade Federal de Lavras. j.aldo@dcf.ufla.br

5 Doutor em Economia Florestal pela University of Toronto, Canadá e Pós-Doutorado pelo Instituto Internacional de Pesquisas Florestais, Tsukuba, Japão. Pesquisador visitante, Universidade Federal de Lavras. jlprezen@ufla.br

6 Doutorando em Engenharia Florestal, Universidade Federal de Lauras. rossiallan@gmail.com 


\section{Introdução}

Estudos e trabalhos de Gestão Ambiental refletem a preocupação da humanidade, no que se refere à utilizaçáo dos recursos naturais, incluindo a necessidade da busca pela forma adequada de exploração, transformação e consumo, para que estas etapas sejam otimizadas e a exaustáo evitada ou protelada por um longo prazo. Até a década de 60 o conceito de desenvolvimento significava apenas crescimento econômico. Dessa forma, a manutençáo da qualidade de vida náo era percebida como fato dependente da qualidade ambiental, e considerava-se incompatível com o desenvolvimento. Entretanto, no final da década de 60 e início de 70, começaram a surgir propostas inovadoras, no que diz respeito à proteçáo ambiental.

Após a Conferência das Nações Unidas sobre o Meio Ambiente Humano (Declaraçáo de Estocolmo), que ocorreu de 5 a 16 de junho de 1972 na Suécia, houve uma mudança no pensamento acerca do meio ambiente (DOTTO e CUNHA, 2010), e consequentemente, esse foi o período no qual iniciaram as maiores preocupaçóes sobre essa temática. Os conceitos abordados nesta conferência contemplaram a necessidade de orientaçáo da sociedade quanto à proteçáo do meio ambiente, principalmente, no que se referia à poluiçáo originada pelas emissóes das atividades industriais (MAGLIO, 2000). Essa conferência enfatizou a necessidade de projetar e programar estratégias para o meio ambiente, no intuito de promover o desenvolvimento social e econômico de forma ambientalmente justa, por meio do emprego de técnicas adequadas de produção. Foram estabelecidos 26 princípios, dentre os quais, buscaram enfatizar a preocupação com a exaustão dos recursos pelo crescente consumo, compatibilizando produçáo e qualidade de vida para as geraçóes atuais e futuras. Em decorrência dos resultados e avanços obtidos a partir da Conferência de Estocolmo, foram realizadas outras conferências com objetivos similares, visando discutir o desenvolvimento sustentável e temáticas correlacionadas.

Novicki (2009) entende que as três conferências (Estocolmo, Rio-92, Johannesburgo) objetivaram consenso sobre a viabilidade do "capitalismo sustentável", preconizando soluçóes de mercado e uma educação conservacionista, ou seja, formas de se obter o desenvolvimento sustentável. Já na Conferência do Rio +20 , que ocorreu em junho de 2012, houve uma retomada 
dos principais conceitos e princípios, assim como avaliaçóes do progresso alcançado e das lacunas existentes nas conferências anteriores, na tentativa de sensibilizar a população mundial para a necessidade de um meio ambiente equilibrado.

Neste contexto, o processo crescente da degradação ambiental no mundo e a pressão de organismos internacionais fizeram com que medidas de controle fossem tomadas no Brasil e os instrumentos de gestáo ambiental em nosso país começaram a se tornar realidade. De acordo com a Lei de Política Nacional do Meio Ambiente (PNMA) - Lei no 6.938/81 - os instrumentos de gestão ambiental são considerados os mecanismos utilizados pela administração pública com o intuito de alcançar os objetivos da política ambiental (BRASIL, 1981).

Varela (2007) enfatiza que os instrumentos de políticas ambientais podem ser diretos ou indiretos. Os primeiros são aqueles elaborados exclusivamente para resolver questóes ambientais (comando e controle) e os indiretos são desenvolvidos para resolver outros problemas, mas acabam colaborando para as soluçóes relativas ao meio ambiente. Quando entram em pauta, os instrumentos de políticas ambientais, geralmente, referem-se aos elementos de comando e controle, os quais se caracterizam pela utilização de formas de regulação direta via legislaçáo e normas. Já os instrumentos indiretos são mecanismos de mercado e podem ser caracterizados pela imposição de taxas, tarifas ou certificados de propriedade.

Nos últimos anos, o debate sobre a escolha de instrumentos de política ambiental no Brasil vem se intensificando (ALMEIDA, 1997). Atualmente observa-se que os instrumentos de comando e controle são os mais utilizados na tentativa de se evitar grandes impactos negativos ao meio ambiente. $\mathrm{O}$ poder legislativo encontra facilidades para criar leis que, no entanto, não atingem a meta de minimizaçáo dos impactos ao meio ambiente, seja pela ineficiência dos agentes fiscalizadores da lei, ou pela inaplicabilidade ou falta de inteligibilidade da lei.

A percepção de que os instrumentos de política nacional, tal como idealizados e executados pelo Estado brasileiro, náo estariam provocando a efetividade adequada frente aos objetivos dessa política no que se refere à conservaçâo ecológica, cria um ambiente para o surgimento de um debate sobre os 
gargalos encontrados pelo sistema de política ambiental brasileiro. Nesse sentido, o objetivo desse trabalho foi descrever os principais instrumentos da política ambiental brasileira, destacando os principais pontos de discussão do tema.

\section{Metodologia}

Esse trabalho foi idealizado em decorrência da necessidade de organizar e compilar dados relacionados à Política Nacional do Meio Ambiente (PNMA), tendo em vista a dificuldade de encontrar referências sobre pesquisas que tratam da análise dos instrumentos de gestáo ambiental. As discussóes realizadas neste trabalho contemplam referências baseadas em artigos científicos da área, assim como teses e dissertaçóes atualizadas. A ideia é associar o maior número de informaçóes, no intuito de contribuir para o debate científico sobre o tema.

Dessa forma, realizou-se uma pesquisa qualitativa (CHIZZOTTI, 2003) do tipo exploratória (PIOVESAN e TEMPORINI, 1995) que possibilitou uma análise crítica sobre os principais gargalos que impedem a efetividade dos instrumentos de gestáo ambiental elencados na Política Nacional do Meio Ambiente brasileira, pois a aprendizagem é potencializada quando parte de fatos ou contextos já conhecidos (PIOVESAM e TEMPORINI, 1995).

\section{Resultados e discussão}

Com a aceleração desordenada da agricultura e da produção industrial após a Segunda Guerra Mundial (1945), tornou-se perceptível a necessidade de encontrar um modelo de desenvolvimento que não ameaçasse à sustentabilidade planetária (FARIAS, 2006). Foi, entretanto, a partir da Conferência das Naçóes Unidas para o Meio Ambiente, de 1972, onde aconteceram debates sobre o desenvolvimento sustentável, considerando-se a partir de entáo, a importância de estudos sobre preservação da qualidade de vida, envolvendo temas relacionados ao ambiente, por meio de protocolos e acordos multilaterais entre países e blocos de países (RIBEIRO, 2010).

De acordo com Cunha e Coelho (2003), no Brasil, ocorreram três momentos na história das políticas ambientais: a) o primeiro período, de 1930 a 1971, foi caracterizado pela construção de uma base de regulação dos usos dos recursos naturais; b) no segundo período, de 1972 a 1987, a açáo intervencionista do Estado chegou ao ápice; c) o terceiro período, de 1988 aos dias atuais, 
caracterizou-se pelos processos de democratização e descentralização decisórias, e pela rápida disseminação dos conceitos de desenvolvimento sustentável. Dessa forma, no país, a política ambiental ganhou arquitetura legislativa somente após a Lei de Política Nacional do Meio Ambiente (PNMA). Assim, em 31 de agosto de 1981 foi publicada a Lei no 6.938, criando a Política Nacional do Meio Ambiente, e estabelecendo conceitos, princípios, objetivos, instrumentos, penalidades, mecanismos de formulação e aplicação, no intuito de estabelecer normas de gestão e proteção dos recursos ambientais.

A gestão ambiental no Brasil tem na PNMA (Lei 9.638/81) sua principal referência, que por sua vez, é fundamentada nos incisos VI e VII do artigo 23 e artigo 225 da Constituição Federal (ROSSI, 2009). Segundo a Lei $n^{\circ}$ 6.938/81, artigo $3^{\circ}$, meio ambiente é considerado como o conjunto de condiçôes, leis, influências e interaçôes de ordem física, química e biológica, que permite, abriga e rege a vida nas diferentes formas. Nesse sentido, observa-se que a amplitude legislativa ambiental abrange o universo animal, vegetal e mineral. Com relação à degradação ambiental, a mesma lei a define como alteração adversa das características do meio ambiente (BRASIL, 1981). Vale lembrar que de acordo com a Resolução CONAMA no 01/86, degradação ambiental está diretamente relacionada com impacto ambiental negativo, no qual, considera-se como degradação da qualidade ambiental ocasionada pela atividade humana (CONAMA, 1986).

Após vários anos de discussão no Congresso Nacional, em 2012 foi publicado o novo Código Florestal Brasileiro, por meio da Lei 12.651/12, regulamentando a proteção da vegetação nativa e revogando a Lei 4.771/65. A publicaçáo desta lei, apesar de ter gerado grande polêmica durante a votaçáo nas casas do Legislativo (Câmara e Senado Federal), atinge um nível de detalhamento que fortalece o conceito de produção econômica sustentável rumo à gestão territorial integrada, valorizando o capital social presente em diferentes realidades (VIEIRA e BECKER, 2010). A redação do novo Código Florestal procurou preencher as lacunas do código anterior de forma mais detalhada. O legislador enfatizou a instituição de áreas de proteção no interior de propriedades rurais, tais como a Área de Preservação Permanente (APP) e Reserva Legal (RL), além da regulação da exploração de produtos florestais e o trato especial à agricultura familiar, considerados ambiental e socialmente importantes para o país. 
A natureza coletiva do meio ambiente impóe ao Poder Público o dever de orientar o uso dos recursos naturais de forma que seja mantida a capacidade produtiva dos diferentes sistemas e compartimentos ambientais (MONTAÑO e SOUZA, 2008), ou seja, o Estado tem a prerrogativa de fazer a avaliação das propostas de intervenção no meio, e estabelecer as condiçóes para que estas se tornem ambientalmente viáveis.

Nesse contexto, a discussão sobre o uso de ferramentas de gestáo pública, passa pelo conceito de externalidades da microeconomia neoclássica. Externalidades ocorrem quando as atividades de produção e/ou consumo geram custos (ou benefícios) que não são adequadamente contabilizados pelo mercado (VARELA, 2007). Destarte, o uso de recursos ambientais pode gerar custos externos (externalidades) negativos intra e intertemporais (MOTTA, 2006).

Os instrumentos de gestão ambiental são utilizados no sentido de evitar essas perdas drásticas (custos externos) no meio ambiente. São as ferramentas utilizadas para a efetiva defesa e proteção do ambiente (SAMPAIO, 2008). Essas ferramentas de controle ambiental estão elencadas na Lei de Política Nacional do Meio Ambiente (PNMA), em seu artigo 9o, e visam regulamentar as várias atividades que abrangem o meio ambiente, para que haja preservação, melhoria e recuperação da qualidade ambiental, tornando o ambiente favorável à vida e a condiçóes propícias para o desenvolvimento social e econômico (RODRIGUES, 2010).

No entanto, de acordo com Sampaio (2008), alguns instrumentos de gestáo ambiental se encontram exaustivamente regulados, outros ainda carecem de elucidação regulamentar específica. Isso contribui para tornar importante um estudo dessa natureza, visto que outro problema é a carência de informaçóes (ROCHA et al., 2010).

\section{I. Análise da efetividade dos instrumentos da Política Nacional do Meio Ambiente (PNMA)}

Diante da complexidade dos interesses sociais, a resolução dos conflitos ambientais requer uma condução compartilhada no processo de gestão. Essa preocupação está explicitada na Constituição de 1988 (art. 225) quando determina que "impóe-se ao poder público e à coletividade o dever de proteger e preservar o ambiente para as presentes e futuras geraçóes” (GOMES, 2008). 
Com o aumento dos riscos das atividades humanas, o poder público viu-se obrigado a ampliar o disciplinamento legal sobre a proteção ambiental, bem como seu papel institucional, criando mecanismos para avaliação dos riscos, visando subsidiar os processos decisórios, a fim de evitar a ocorrência de danos ambientais (MASCARENHAS, 2009). Souza (2005) ensina que as regras jurídicas existem para regulamentar os fatos e atos da vida social, porém, algumas vezes observa-se certa dúvida sobre a efetividade dessas regras diante do objetivo pretendido, quando se refere à realização e praticidade, segundo a capacidade de adequação do comportamento social de acordo com a previsão normativa. A efetividade da norma jurídica é a sintonia adequada entre as suas previsóes genéricas, abstratas, impessoais, e o fato social que ela se propóe a normatizar (BUENO, 2009).

Os instrumentos da Política Nacional do Meio Ambiente são ferramentas da política ambiental brasileira que visam conter as atividades econômicas que ameaçam determinado sistema ambiental, a partir de medidas preventivas e coibitivas, traduzindo-se em normas de comando e controle, visando à regulamentação das atividades de potencial impacto ambiental. Traduzem-se em restriçóes de atividades, controle do uso de recursos naturais e especificação de tecnologias.

A legislação brasileira é clara em seus princípios e objetivos, porém, quando se trata das atribuiçôes para execução da política ambiental, não se mostra específica o suficiente. Mesmo fazendo menção ao Sistema Nacional do Meio Ambiente - SISNAMA - (artigo 8º, PNMA), observa-se certa restrição para apreciaçáo de estudos de impactos ambientais e respectivos relatórios como sendo competência do CONAMA (ROSSI, 2009).

Dessa forma, os efeitos dos instrumentos de gestão de controle ambiental muitas vezes são questionados, pois, não é simples manter o desenvolvimento econômico e conter o avanço da degradaçáo ambiental. Nesse sentido, há certa insegurança quanto à aplicabilidade desse direito (TOMIYAMA, 2009).

Braga (2010) cita duas deficiências importantes que comprometem a base da estrutura institucional responsável pela formulação e aplicação das normas ambientais brasileiras, que são: o grande número de instâncias decisórias com o potencial para a edição de normas ambientais (descentralizaçáo de poderes) e a baixa qualidade das regras que disciplinam o processo administrativo de 
produção normativa no CONAMA. Somado a isso, verifica-se ainda problemas advindos da burocracia exagerada, falta de profissionais que atuam na sua devida área de formação; problemas na fiscalização por parte dos órgãos competentes; problemas de logística; falta de equipamentos adequados para fiscalização e programas integrados de educação ambiental.

\section{I.2. Padrões de qualidade ambiental}

O artigo $8^{\circ}$ da Lei 6.938/81 delega poderes ao CONAMA de estabelecer normas, critérios e padróes relativos ao controle e à manutenção da qualidade do meio ambiente com vistas ao uso racional dos recursos ambientais. Segundo a política ambiental, o termo qualidade ambiental pode ser conceituado como juízo de valor atribuído ao quadro atual ou às condiçóes do meio ambiente em que os níveis de poluição não comprometam a saúde da população (IBAMA, 2002).

O estabelecimento de padróes de qualidade ambiental confere às instituiçôes brasileiras o cumprimento das resoluçóes do CONAMA referente à manutenção da qualidade do meio ambiente (GUIMARÁES, 2009). Na gestão ambiental, são de uso corrente os padróes de qualidade dos componentes do meio ambiente, o ar, a água e o solo; bem como os padróes para a emissáo de poluentes (IBAMA, 2002).

Os primeiros padróes de qualidade do ar do país foram estabelecidos em 1976 (Portaria no 31/76 do antigo Ministério do Interior). Após esse período o CONAMA promoveu a revisão desta portaria, instituindo o Programa Nacional de Qualidade do Ar (PRONAR), mediante a aprovação da Resolução CONAMA no 005/89, que estabeleceu os padróes de qualidade do ar, criou a rede nacional de monitoramento da qualidade do ar, bem como o inventário das fontes e dos poluentes atmosféricos (IBAMA, 2002). No entanto, foi complementada pelas Resoluçóes no 03/90, 08/90 e 436/2011.

Dentre as Resoluçóes do CONAMA que tratam de padróes de qualidade ambiental, destaca-se também a Resolução CONAMA 020/86, que estabelece os primeiros limites e padróes de qualidade das águas, de acordo com critérios de salinidades adequados para diferentes tipos de uso, classificando-as em: águas doces, salobras e salinas - hoje esta classificação é contemplada pela Resolução CONAMA 357/05. Já a Resolução 03/90, complementada pela 
Resolução 08/90, dispóe sobre qualidade do ar e concentraçóes de poluentes permitidas. Essa é uma tentativa expressa de prevenir graves e iminentes riscos à saúde da população.

Com relação aos níveis de ruído, o principal aspecto, refere-se à observância do limite considerado como aceitável para áreas habitadas, visando o conforto acústico da comunidade, segundo a NBR 10.152 - Avaliação de Ruído em Áreas Habitadas da Associação Brasileira de Normas Técnicas (ABNT). Quando não existem padrôes específicos nacionais, muitas vezes são utilizadas normas internacionais, tais como os padróes definidos pela Organização Mundial de Saúde (OMS) ou ainda padróes aplicados em outros países (IBAMA, 2002).

Esses padrões de qualidade ambiental consideram, além dos critérios cientificamente estabelecidos, a disponibilidade de métodos analíticos, de tecnologia de tratamento para remoção ou redução dos agentes tóxicos aos níveis desejados, fatores políticos, econômicos e sociais do país, que sáo definidos através de processos denominados gerenciamento do risco (USEPA, 1991).

Nesse contexto, a produção das normas na legislação brasileira traduz o conflito social, ou seja, os vários setores da sociedade dividem diferentes valores, referentes a deveres e obrigaçóes sociais. Denota-se, entáo, que a problemática ambiental se origina dos usos conflitantes gerados, tanto pelas diversas demandas da sociedade em relaçáo a um determinado recurso ou sistema ambiental, quanto pelas próprias alterações das condiçóes ambientais (AGRA FILHO, 2008). Diante disso, acredita-se que a ideia de padróes de qualidade ambiental prevista no artigo $9^{\circ}$ da Política Nacional do Meio Ambiente encontra-se ameaçada pelos valores da sociedade contemporânea, pois, o modelo de desenvolvimento adotado gera grande desigualdade social e requer a produção ilimitada de alimentos, energia e bens de consumo, gerando, em larga escala, a produção de detritos tóxicos e elementos residuais não biodegradáveis (BORGES et al., 2009).

\section{I.3. Zoneamento ambiental}

O Zoneamento Ambiental, também conhecido como Zoneamento Econômico-Ecológico (ZEE), surgiu a partir da admissáo por parte do Estado brasileiro que a ocupação desordenada do território nacional é a responsável 
por inúmeros prejuízos de cunho sócio-ambiental (LEITE, 2001). Esta é uma regra estabelecida pela administração pública que impóem restriçôes ao direito de uso da propriedade privada em sintonia com os princípios constitucionais estabelecidos pela carta de 1988 (GUIMARÃES, 2009). Sua finalidade é exercer um controle espacial das atividades, porém com o crescimento desenfreado das grandes cidades e a falta de fiscalização adequada, fica difícil fazer valer as regras estipuladas pela legislação (VARELA, 2007).

A formalização do ZEE foi uma indução a um processo de ordenamento territorial, cujo resultado significa o uso sustentável dos recursos naturais (LEITE, 2001). Seu conteúdo envolve diagnóstico e prognóstico sobre potencialidades e fragilidades de determinadas regióes, sob o ponto de vista de seus recursos. A identificaçáo dessas áreas visa limitar seu uso no sentido de evitar danos ao meio ambiente.

Segundo Leite (2001), o processo que envolve o ZEE apresenta uma série de problemas, os quais podem compreender os princípios relativos à gestáo ambiental na busca de bases sustentáveis. $\mathrm{O}$ zoneamento em sua essência acaba fazendo proposiçóes do uso de recursos dentro de limites pré-estabelecidos ou capacidade de suporte dos ecossistemas.

Adotar esses princípios sugere mudanças de concepçóes dos agentes envolvidos, o que, possivelmente, pode ser um fator de geração de conflitos sociais, considerando os interesses individuais de cada cidadão. Além disso, observa-se certa complexidade diante das articulaçóes que norteiam a implementação de um zoneamento, ou seja, cada unidade federativa propóe seus aspectos, diante das especificidades regionais observadas nos fatores bióticos e abióticos contemplados pelo seu zoneamento ambiental.

Alguns aspectos dificultam a implementação do ZEE, dentre os quais, citam-se: este método se refere apenas a pressupostos; ocorrem falhas de comunicação junto à comunidade diretamente afetada; há ausência de relações interinstitucionais para sua implementaçáo; falta de negociaçóes com os setores políticos e econômicos; carência de mecanismos efetivos para a resolução de conflitos (LEITE, 2001). No entanto, vale ressaltar que o ZEE náo se presta a resolver todas as questóes de ordenamento territorial. Ele é uma proposta técnica que se bem elaborada, subsidiará condiçôes para a tomada de decisão dos atores sociais que são os políticos, governantes e a sociedade em geral (GUIMARÃES, 2009). 
De acordo com Montaño et al. (2007), zoneamento ambiental é o instrumento mais adequado para a obtençáo de respostas amplas com relação à viabilidade da ocupação do território em bases ambientalmente sustentáveis, pois contempla fatores ambientais a serem considerados, como por exemplo, na delimitação das áreas de influência e/ou identificação de conflitos. Sendo assim, trata-se de uma ferramenta essencial para a efetividade de outros instrumentos.

De maneira geral, o Ministério do Meio Ambiente (MMA) preconiza diretrizes metodológicas para o delineamento de uma concepção de ZEE, nas quais, consideram-se os arranjos institucionais, os fundamentos conceituais e os procedimentos operacionais necessários à execução do ZEE no território nacional. Dentre as principais temáticas, encontram-se o planejamento, diagnóstico, prognóstico e por fim, os subsídios à implementação do zoneamento, que além de identificar as demandas locais, consideram também o meio físico e biótico, assim como a organização jurídica e institucional, culminando com o apoio à aplicação dos resultados no final da análise, por parte dos agentes dos órgãos ambientais. As diretrizes metodológicas estão orientadas, principalmente, para assegurar a efetividade de dois aspectos: 1) proporcionar base técnico-científica e operacional ao planejamento estratégico em nível federal; 2) apoiar técnica e operacionalmente as iniciativas de projetos de ZEE no país (MMA, 2006).

\section{I.4. Avaliação de Impacto Ambiental ( $A \mid A)$}

De acordo com Sánches (2008), Avaliação de Impacto Ambiental (AIA) visa identificar ou prever os principais impactos de um empreendimento que possam comprometer a qualidade do meio ambiente. Para cumprir os objetivos do estudo de impacto ambiental é preciso considerar duas medidas: a primeira refere-se à identificação das variáveis que devem ser avaliadas; a segunda, trata-se da importância do impacto causado por um determinado empreendimento na variável avaliada (GUIMARĀES, 2009). Nesse sentido, estudos atuais de impacto no ambiente não consideram os efeitos cumulativos causados por outros empreendimentos dentro de uma esfera maior de tempo e espaço. Assim, mesmo com a avaliação prévia e monitoramento a posteriori, não existe a garantia de efetividade no processo dos estudos de impacto ambiental (GUIMARÁES, 2009). 
Prado Filho e Souza (2004), afirmam que a disparidade quanto à indicação e à implantação das medidas de controle ambiental estabelecidas nos EIA/RIMAs em uma avaliaçáo de impacto, colocam em risco a efetividade desse instrumento. No Estudo de Impacto Ambiental (EIA), Prado Filho (2001) destaca que os empreendedores não conseguem observá-lo como um instrumento complementar de processo decisório e, assim, não observam sua abrangência num contexto mais global.

Outros problemas encontrados no processo de AIA podem ser destacados, tais como: a ausência de diretrizes e manuais apropriados para a sua realização; a falta de recursos humanos disponíveis e qualificados; a aplicação desnecessária desse procedimento; a não realização da AIA nas políticas, planos e programas (OLIVEIRA e BURSZTYN, 2001), e, além disso, muitas vezes o empreendedor interpreta a aprovação do EIA/RIMA como fato decorrente da obrigação do pagamento pelo estudo realizado, desconsiderando então o ponto de vista ambiental e a viabilidade do seu empreendimento.

\subsubsection{Licenciamento e a revisão de atividades efetiva ou potencialmente poluidoras}

O despertar para a questão ambiental, no Brasil, se configurou notadamente com a instituição da Lei Federal n ${ }^{\circ}$ 6.938/81, que tornou o Licenciamento Ambiental procedimento obrigatório (ANDRADE, 2007), diante de atividades com potencial para causar impactos negativos ao meio ambiente.

Segundo Montaño et al. (2007), o principal objetivo do licenciamento ambiental é promover uma análise sobre a viabilidade ambiental das atividades econômicas, assegurando que os empreendimentos sejam instalados em locais ambientalmente adequados e seus responsáveis adotem tecnologias que minimizem os possíveis impactos negativos sobre o ambiente, isto é, tornando-os viáveis do ponto de vista ambiental. Sánches (2008) considera o licenciamento como um dos instrumentos mais importante da PNMA, pois finaliza o sistema com a autorização governamental para a realização de atividades que utilizam recursos ambientais ou que tenham potencial de causar degradação. De acordo com a Lei 6938/81 (artigo $1^{\circ}$ ), "A construção, instalação, ampliação e funcionamento de estabelecimentos e atividades utilizadoras de recursos ambientais, considerados efetiva ou potencialmente poluidores, [...] dependerão de prévio 
licenciamento de órgão estadual competente e do Instituto Brasileiro do Meio Ambiente e dos Recursos Naturais Renováveis" (BRASIL, 1981).

A Política Nacional do Meio Ambiente (PNMA) utiliza o licenciamento ambiental como forma de disciplinar e regulamentar a utilizaçáo dos recursos ambientais; é considerado como um procedimento administrativo que visa prevenir danos ambientais (SÁNCHES, 2008), porém, excessivamente burocrático, caro, que atrasa a conclusão de inúmeras e essenciais obras de infra-estrutura (BRAGA, 2010).

Braga (2010) afirma que há uma corrente de pensamento que considera o licenciamento ambiental um instrumento sem efetividade para a proteção do meio ambiente. $\mathrm{O}$ autor afirma que há falhas no desenho institucional dos órgãos ambientais que impedem ou dificultam que seja criado e mantido um conjunto de normas jurídicas efetivas para o licenciamento ambiental. Essas falhas, muitas vezes são decorrentes da descentralização de poderes, refletida pela grande quantidade de órgáos ambientais; o que pode resultar na demora do processamento de investigação e penalização dos infratores.

Além dessa necessidade de maior rigor na comunicação entre os órgãos federal (IBAMA) e estaduais responsáveis pelo licenciamento ambiental, Montańo et al. (2007) afirmam que, outro fator que impede este instrumento de atingir seu objetivo é a deficiência na execução de outros instrumentos da PNMA, pois existe uma relação de complementariedade entre os mesmos.

\section{I.6. Criação de espaços territoriais especialmente protegidos pelo poder público}

$\mathrm{Na}$ Constituição Federal de 1988, no capítulo referente ao meio ambiente, o legislador menciona, no caput do artigo 225, o direito de todos ao meio ambiente ecologicamente equilibrado. E para a efetividade desse direito, a Constituição impóe de forma geral o dever da coletividade e do Poder Público de preservar o meio ambiente. A legislaçáo atribui ao poder público o dever de definir espaços territoriais a serem especialmente protegidos, de alteração e supressão permitidas somente por meio de lei (PEREIRA e SCARDUA, 2008). Nesse sentido, observa-se que a legislação que criou um espaço territorialmente protegido, não o conceitua nem delimita sua abrangência. $O$ que se observa é a simples exigência de que esses espaços sejam criados. 
Os espaços territoriais especialmente protegidos referem-se a qualquer parcela do território nacional que seja merecedora de proteção ambiental e vincula o uso dos recursos naturais encontrados, às prescriçóes definidas em norma legal (SCARDUA, 2003); eles não se confundem com Unidades de Conservação (UC) ou áreas de conservação (PEREIRA e SCARDUA, 2008).

Esses espaços visam à preservação e à proteção da integridade de amostras de toda a diversidade de ecossistemas, e também, à proteçáo ao processo evolutivo das espécies, capaz de abarcar todos os demais conceitos de áreas protegidas e UCs, estabelecidos posteriormente por normas infraconstitucionais (PEREIRA e SCARDUA, 2008), incumbindo-se aos poderes públicos ou privados a competência de criá-los e mantê-los.

Conceitua-se como espaços territoriais especialmente protegidos os seguintes estatutos criados pelos poderes públicos e privado: 1) Unidades de Conservação; 2) áreas protegidas; 3) quilombos; 4) áreas tombadas; 5) monumentos arqueológicos e pré-históricos; 6) áreas especiais e locais de interesse turístico; 7) reserva da biosfera; 8) corredores ecológicos e zonas de amortecimento; 9) Floresta Amazônica, Mata Atlântica, Serra do Mar, Pantanal Mato-grossense e Zona Costeira; 10) jardins botânicos, hortos florestais e jardins zoológicos; 11) terras devolutas e arrecadadas necessárias à proteção dos ecossistemas naturais; 12) áreas de preservação permanente e reservas legais; e 13) mega espaços ambientais (PEREIRA, 2006). Vale ressaltar que Unidades de Conservação são aquelas contempladas no rol da Lei 9.985/2000 Sistema Nacional de Unidades de Conservação - SNUC (PEREIRA e SCARDUA, 2008).

Para um espaço ser considerado especialmente protegido, deve conferir proteção ao meio ambiente (PEREIRA e SCARDUA, 2008). Em alguns casos, as restriçôes constitucionalmente previstas para estes espaços são de difícil aplicação prática, como no caso das reservas legais e áreas de preservação permanente. Considerando-se que o intuito do legislador constituinte foi exigir leis casuísticas, tais restriçóes acabam por se mostrarem inócuas (PEREIRA e SCARDUA, 2008), quando confrontada a força da lei com o interesse social e utilidade pública, também previstos na legislação brasileira.

Outro problema observado frente à administração de espaços territoriais especialmente protegidos é atribuído ao fato de muitos deles ainda estarem em processo de regularizaçáo fundiária, assunto de alta complexidade e 
tratados com baixo grau de prioridade (ROCHA et al., 2010). Atualmente no Brasil, muitas das UCs apresentam esse problema, e tem sua gênese e sua conservação tensionadas pela questão fundiária (KURY, 2009).

O processo de regularização fundiária desses espaços prioriza a proteção da natureza sem ignorar o direito de propriedade do particular, visto que, dá o direito de indenização ao desapropriado e o seu reassentamento. Esse processo trata da transferência de domínio de uma determinada propriedade, constante no interior de uma UC, para o ente público correspondente (KURY, 2009), federal, estadual, municipal ou distrital.

\section{I.7. Aplicação de penas e fiscalização}

Foi a partir da Revoluçáo Industrial (1789) movimentada pelo espírito capitalista (MIRANDA, 2012) que a interferência humana no ambiente natural tornou-se mais intensa (DACROCE, 2009), porém, somente na década de 70 intensificaram-se as discussóes relacionadas à escassez dos recursos ambientais. Segundo Caradori (2008), a fiscalização do uso dos recursos ambientais, faz referência às açóes estratégicas definidas pelo Poder Público através de seus órgáos especializados em meio ambiente.

Ressalta-se ainda a criação da Lei dos Crimes Ambientais (Lei 9.605/98), a qual "dispóe sobre as sançôes penais e administrativas derivadas de condutas e atividades lesivas ao meio ambiente, e dá outras providências" (BRASIL, 1998). Esta lei proporcionou o grande salto para aplicação de penas e a fiscalização ambiental, pois os delitos eram considerados contravençóes penais e, somente após a criação desta lei é que o "crime ambiental" foi tipificado na legislação brasileira.

No entanto, observando a efetividade dos instrumentos da Política Nacional do Meio Ambiente, verificam-se dúvidas quanto aos efeitos que de fato justificam sua existência. De acordo com Brito e Barreto (2005), apenas 2\% dos infratores foram criminalmente punidos em uma amostra de 55 casos judiciais contra infração ambiental no setor florestal no Pará entre 2000 e 2003. Alguns problemas podem ser identificados, como erro de preenchimento dos autos de infração; deficiência da base de dados e demora nos procedimentos de investigaçáo e defesa, além da inadimplência no pagamento das parcelas de multas. 
Nesse sentido, a aplicação do instrumento citado no artigo $9^{\circ}$, inciso IX (Lei 9605/98), no qual são propostas penalidades disciplinares ou compensatórias ao não cumprimento das medidas necessárias à preservação ou correção da degradação ambiental, em alguns casos, apresenta defasagem no sistema, em virtude de açóes desarticuladas dos órgãos de fiscalização ambiental (MARÇAL, 2006).

\section{I.8. Garantia da prestação de informações relativas ao meio ambiente}

Outro instrumento de gestão ambiental preconizado pela PNMA é a garantia da prestação de informaçóes relativas ao meio ambiente. Há evidências que a política nacional obriga o poder público não somente a informar sobre a situação da qualidade ambiental, como também produzi-las quando na sua inexistência. Observa-se que de todos os instrumentos listados na PNMA, cinco deles estáo estritamente ligados à publicidade das informaçóes, (ROSSI, 2009), que são: incisos VII, VIII, X, XI e XII.

Essa obrigação deveria ser igual, por exemplo, às exigências de uma atividade pendente de licenciamento, que depende de informaçóes dos órgáos competentes para a realização das atividades, para que haja celeridade no processo de estudo ambiental. Estas informaçóes são fundamentais para os interesses do particular proponente do projeto, assim como, interesses também da coletividade.

Nesse sentido, considerando a possível não aplicação deste instrumento da política ambiental brasileira, se remeteria uma deficiência na operaçáo dos demais instrumentos, configurando uma desestruturação dessa política pública, o que pode implicar em evidentes danos ao bem jurídico em questão, principalmente danos ao meio ambiente.

Barros (2004) descreve a insuficiência da sistematizaçáo e a falta de melhor estruturação dos sistemas de informação existente, como um problema, por serem compostos e apresentados de forma dispersa. Raras são as preocupaçóes em se criar sistemas de informaçóes compartilhadas, e nesse contexto, observa-se a carência de transversalidade na gestão da informação ambiental, que por sua vez, necessita de dinâmica multidisciplinar (ROSSI, 2009). 
Machado (2006) afirma que a disponibilização das informações é tratada claramente para governo e entre governantes, e nesse caso, o público é prejudicado. Como se isso náo bastasse, algumas restriçóes de acesso a informação são justificadas por questóes de interesses particulares. Portanto, o direito de propriedade intelectual abrange direitos autorais acerca de produçóes intelectuais (ROSSI, 2009), fato que pode dificultar o acesso às informaçóes relativas ao meio ambiente.

\subsubsection{Incentivos à produção e instalação de equipamentos voltados para a melhoria da qualidade ambiental}

Outra preocupação quando se discute as diferentes possibilidades de degradação frente à implementação de determinado projeto está relacionada com a forma e os tipos de equipamentos a serem utilizados com menor capacidade impactante ao meio ambiente. Diante de uma crescente preocupaçáo ambiental, percebe-se a necessidade de mensurar (FARIA et al., 2009) os efeitos causados na aplicação de ativos ambientais, ou seja, os efeitos provenientes de investimentos de recursos econômicos no que se refere à insumos em geral, bem como investimentos em máquinas, equipamentos e instalaçóes visando diminuir os impactos ambientais.

A redução de impactos ocasionados pelas emissóes de gases de efeito estufa (GEE) tratados no Protocolo de Kyoto em 1997 (MOTTA et al., 2000), requer, em sua essência, a utilizaçáo de maquinários eficientes na implementação de um projeto de engenharia. Esse Protoloco prioriza projetos de Mecanismos de Desenvolvimento Limpo (MDL), no intuito de promover a conservação ambiental.

Dessa forma questiona-se: Como projetos de MDL aumentam o fluxo de investimentos para os países em desenvolvimento? Quais as exigências dos financiadores dos projetos? Será que de fato há igualdades nos investimentos durante o processo de financiamento? Nessa ótica, ressalta-se, que, na maioria dos casos, somente as grandes empresas são beneficiadas por projetos que contemplam a aquisiçáo de equipamentos de alta tecnologia. E, no geral, são essas empresas que estão regularizadas no contexto das exigências das certificadoras, principalmente da série ISO.

Sem uma avaliação cuidadosa desses atributos indiretamente associados à reduçáo de emissóes de carbono, existe o risco de que o MDL torne-se um instrumento de redução de custo para países desenvolvidos, legitimados por 
benefícios secundários ocasionais que podem ou não ser consistentes, considerando-se as prioridades dos países em desenvolvimento (MOTTA et al., 2000).

\section{I.I0. Cadastro técnico federal de atividades e instrumentos de defesa ambiental}

O Cadastro Técnico das atividades com potencial de degradação ambiental deve ser realizado junto ao Instituto Brasileiro do Meio Ambiente e dos Recursos Naturais Renováveis - IBAMA, seguindo o que determina a Instrução Normativa (IN) nº 37 de 2004. Na referida IN, é especificado em seu artigo $2^{\circ}$ que: "Todo produtor, importador, exportador, comercializador e usuário de quaisquer das substâncias, controladas ou alternativas pelo Protocolo de Montreal, bem como os centros de coleta e armazenamento e centros de regeneraçáo ou reciclagem, pessoas físicas ou jurídicas, devem estar registrados no Cadastro Técnico Federal de Atividades Potencialmente Poluidoras, gerenciado pelo IBAMA" (BRASIL, 2004). As atividades sujeitas ao controle pelo Protocolo de Montreal são aquelas com potencial de liberar substâncias que destroem a camada de ozônio - SDO.

Esse registro visa possibilitar ao IBAMA a implementação de procedimentos sistematizados para o controle e monitoramento da produçáo, importaçáo, comercializaçáo, usuários, coleta, armazenamento e regeneração ou reciclagem de substâncias que destroem a camada de ozônio (SDO), em atendimento ao estabelecido no Protocolo de Montreal ( $\left(1^{\circ}\right.$, IN n $\left.{ }^{\circ} 37 / 2004\right)$.

Ressalta-se que o cadastro de atividades com potencial de degradação ambiental é uma forma de definir políticas públicas, tanto no âmbito da defesa ambiental quanto do reconhecimento de regióes com aptidão para o desenvolvimento, baseando-se nas especificidades locais e na exploração de um determinado recurso. A organização de um sistema eficiente de cadastro de empreendimentos utilizadores de recursos florestais estimula uma ação conjunta dos órgáos e demais setores da sociedade, envolvidos direta ou indiretamente nas questôes ambientais, e a definição de medidas de controle ambiental, a fim de subsidiar, orientar e definir políticas de gestão socioeconômicas em alicerces ambientalmente seguros (CUNHA e BORGES, 2010). 


\section{Considerações Finais}

Para a eficácia da legislação ambiental, por meio da utilização dos instrumentos da PNMA, é necessária mais do que a normatização das vias de comando e controle. São imprescindíveis outras políticas públicas, como a conscientização de políticas educacionais com investimentos nos aspectos voltados para a sustentabilidade, mudança de hábitos de consumo e estilo de vida.

A construção de medidas inovadoras para os processos produtivos deveriam estar calcadas no fortalecimento das medidas preventivas, de acordo com o que preconiza a PNMA em seu artigo $2^{\circ}$, quando traçou seus objetivos. No entanto, esta política prioriza as medidas de comando e controle, como já observado, que se consubstanciam em exigências legais e mecanismos que visam assegurar o seu devido cumprimento, configurando-se em sançôes administrativas e penais.

O modelo ideal, entấo, será aquele que reúna os instrumentos de comando e controle, que influenciam diretamente os atos do poluidor, limitando suas açóes; instrumentos econômicos que afetam o custo-benefício dos agentes e a sensibilização de todos frente o desenvolvimento sustentável, que será mais eficiente quando forem estabelecidas políticas integradas de educação ambiental em todos os níveis da sociedade. $\mathrm{Na}$ verdade, esses instrumentos são complementares e não excludentes, no sentido de sofrerem interdependência e necessitarem ser percebidos no mesmo nível de importância.

Uma lei só é eficiente se for eficientemente aplicada, cumprida e assimilada pelos agentes sociais. Nessa visão, a PNMA precisa ser mais bem divulgada e correlacionada com a Constituição Federal de 1988. Ter boas leis é o primeiro e mais importante passo, mas não basta. A norma é apenas um ponto de partida. Para a sua efetividade, é necessário estabelecer condições que viabilizem sua aplicação, como a contratação de técnicos especializados, infraestrutura adequada e recursos financeiros para a consecução dos trabalhos, além de um público instruído e sensibilizado com as questóes ambientais.

\section{Referências}

AGRA FILHO, S. S. Conflitos ambientais e os instrumentos da política nacional de meio ambiente. eGesta, Santos, v. 4, n. 2, p. 127-140. 2008. 
Breve análise dos instrumentos da política de gestão ambiental brasileira| Dalmo Arantes Barros - Luís Antônio Coimbra Borges Gleisson de Oliveira Nascimento - José Aldo Alves Pereira - José Luiz Pereira de Rezende - Rossi Alan Silva

ALMEIDA, L. T. de. O debate internacional sobre instrumentos de Política ambiental e questóes para o Brasil. Brasília. Disponível em: http://www.ecoeco.org.br. Acesso em: 30/05/201. 1997.

ANDRADE, A.B. Análise do sistema de licenciamento ambiental do município de viçosa, minas gerais. Dissertaçáo (Mestrado). Ciência Florestal. Universidade Federal de Viçosa, Viçosa. 85p. 2007.

BARROS, L. V. A efetividade do direito à informação ambiental. Dissertação (Mestrado). Universidade de Brasília. Centro de Desenvolvimento Sustentável, Brasília. 230p. 2004.

BORGES, L. A. C; REZENDE, J. L. P de; PEREIRA J. A. A. Evolução da legislação ambiental no Brasil. Revista em Agronegócios e Meio Ambiente, Maringá, v. 2, n. 3, p. 447-466. 2009.

BRAGA, A. de C. O. P. Normas abertas e regras no licenciamento ambiental. Dissertação (mestrado). Escola de Direito de São Paulo, São Paulo. 132p. 2010.

BRASIL. Instruçáo Normativa, IN no 37, de 29 de junho de 2004. Diário Oficial da União DOU - no 124. 2004. Disponível em: http://www.ibama.gov.br/cadastro/in37\%2029062004.pdf. Acesso: 11/07/11.

BRASIL. Lei 12.651, de 25 de Maio de 2012. Disponível em: http://www.planalto.gov.br/ ccivil_03/_Ato2011-2014/2012/Lei/L12651.htm. Acesso em: 18/09/2012.

BRASIL. Lei 6.938, de 31 de agosto de 1981. Disponível em: http://www.sigam.ambiente.sp.gov. br/sigam2/legisla\%C3\%A7\%C3\%A3o\%20ambiental/lei\%20fed\%201981_6938.pdf. Acesso: $11 / 07 / 11$.

BRASIL. Lei 9.605, de 12 de fevereiro de 1998. Lei dos Crimes Ambientais. Disponível em: http://www.mma.gov.br. Acesso em: 09/10/2012.

BRITO, B.; BARRETO, P. Aplicação da lei de crimes ambientais pela Justiça Federal no setor florestal do Pará. Revista de Direito Ambiental, 37: 218-243. 2005.

BUENO E. T. Efetividade dos direitos sociais. Revista Internacional de Direito e Cidadania, n. 4, p. 39-43. 2009.

CARADORI, R. da C. Instrumentos de controle na proteçáo legal das florestas. Dissertação (Mestrado). Direito Ambiental. Universidade Católica de Santos, Santos. 263p. 2008.

CHIZZOTTI, A. A pesquisa qualitativa em ciências humanas e sociais: evolução e desafios. Revista Portuguesa de Educação, Braga, Portugal, v. 16, n. 2, p. 221-236. 2003.

CUNHA, S.; COELHO, M. C. Política e gestáo ambiental. In: CUNHA, S. \& GUERRA, A. (Orgs). A questão ambiental. Diferentes abordagens. Rio de Janeiro: Bertrand Brasil, 248 p. 2003. 
CUNHA, V. L. C. de M.; BORGES, L. A. C. Cadastro de consumidores de matéria-prima de origem florestal do Ceará. Revista Ambiência, Guarapuava, v. 6, n. 2, p. 323 - 336. 2010.

DACROCE, G. L.; KONRAD, O. Aspectos Constitucionais da Defesa e Proteção do Ambiente no Brasil. Estudo \& Debate, v. 16, n. 1, p. 49-65, 2009.

DOTTO, A. C.; CUNHA, D. da R. Tutela ambiental constitucional. CEPPG - CESUC - Centro de Ensino Superior de Catalão, n. 22, p. 187-198. 2010.

FARIA, R. C.; LUZ, F. J.; DIAS, L. M. A.; URBANAVICIUS JUNIOR, V. A contabilidade como uma ferramenta para a gestáo ambiental. In: V Congresso Nacional de Excelência em Gestão. 16 p. 2009.

FARIAS, T. Princípios gerais do direito ambiental. Revista prim@ facie, Paraíba, v. 5, n. 9, p. 126-148. 2006.

GOMES, A. Legislação ambiental e direito: um olhar sobre o artigo 225 da constituição da república federativa do Brasil. Revista Científica Eletrônica de Administraçáo, Garça, Ano VIII, n 14.8 p. 2008.

GUIMARÃES, M. A. Análise da política de meio ambiente e da diretriz estratégica de gestão ambiental do exército brasileiro. Dissertação (Mestrado). Centro de Desenvolvimento Sustentável. Universidade de Brasília, Brasília. 117p. 2009.

IBAMA. Guia de Procedimentos do Licenciamento Ambiental Federal - Documento de Referência. Brasília. 128 p. 2002.

IBAMA: Cadastro Técnico Federal. Disponível em: Disponível em: http://www.ibama.gov.br/ cadastro/cadastro.htm. Acesso: 03/07/2011.

KURY, K. A. Regularização fundiária em Unidade de Conservação: o caso do Parque Estadual do Desengano/RJ. Boletim do Observatório Ambiental Alberto Ribeiro Lamego, Campos dos Goytacazes/Rio de Janeiro, v. 3, n. 2, p. 75-89. 2009.

LEITE, C. M. C. O zoneamento ecológico-econômico: impasse e perspectivas de um instrumento de gestáo ambiental. Dissertaçáo (Mestrado). Departamento de Geografia Instituto de Ciências Humanas. Universidade de Brasília, Brasília. 140p. 2001.

MACHADO, P. A. L. Direito a informação e meio ambiente. São Paulo: Malheiros. 288 p. 2006. MAGLIO, I. C. A descentralizaçáo da gestáo ambiental no Brasil: o papel dos órgáos estaduais e as relaçóes com o poder local, 1990/1999. Dissertação (Mestrado). Departamento de Saúde Ambiental. Faculdade de Saúde Pública, São Paulo. 270p. 2000. 
Breve análise dos instrumentos da política de gestão ambiental brasileira| Dalmo Arantes Barros - Luís Antônio Coimbra Borges Gleisson de Oliveira Nascimento - José Aldo Alves Pereira - José Luiz Pereira de Rezende - Rossi Alan Silva

MARÇAL, C. Licenciamento e fiscalização ambiental pelos consórcios públicos. Dissertação (Mestrado). Centro de Desenvolvimento Sustentável. Universidade de Brasília, Brasília. 211p. 2006.

MASCARENHAS, L. M. de A. Interdisciplinaridade, instrumentos legais de proteçáo ao meio ambiente e perícia ambiental. Tese (Doutorado). Programa de Ciências Ambientais. Universidade Federal de Goiás, Goiás. 219p. 2009.

MIRANDA, F. S. M. P. A Mudança do Paradigma Econômico, a Revolução Industrial e a Positivação do Direito do Trabalho. Revista Eletrônica Dereito, v. 3, n. 1, p. 1-24, 2012.

MMA. Ministério do Meio Ambiente. Diretrizes Metodológicas para o Zoneamento Ecológico - Econômico do Brasil. Brasília: 2006. Disponível em: http://www.mma.gov.br/component/k2/ item/7529-diretrizes-metodol\%C3\%B3gicas. Acesso em: 18/09/2011.

MONTAÑO, M.; OLIVEIRA, I.S.D. de; RANIERI, V.E.L.; FONTES, A.T.; SOUZA, M.P. de. O zoneamento ambiental e a sua importância para a localizaçâo de atividades. Revista Pesquisa e Desenvolvimento Engenharia de Produçáo, Itajubá, nº. 6, p. 49- 64. 2007.

MONTAÑO, M.; SOUZA, M.P. de. A viabilidade ambiental no licenciamento de empreendimentos perigosos no Estado de São Paulo. Engenharia Sanitária e Ambiental, Rio de Janeiro, v. 13, n. 4, p. 435-42. 2008.

MOTTA, R. S. da. Economia Ambiental, Rio de Janeiro, FGV Editora. 2006.

MOTTA, R. S. da; FERRAZ, C.; YOUNG, C. E. F.; AUSTIN, D.; FAETH, P. O mecanismo de desenvolvimento limpo e o financiamento do desenvolvimento sustentável no Brasil. Texto para discussão, n. 761.46 p. 2000.

NBR 10.152 - Níveis de Ruídos para o Conforto Acústico. Disponível em: http://www.fat.uerj.br/ educacaoambiental. Acesso: 11/07/11.

NOVICKI, V. Educação para o desenvolvimento sustentável ou sociedades sustentáveis?. Linhas Críticas, Brasília, v. 15, n. 29, p. 215-232. 2009.

OLIVEIRA, A. A. de; BURSZTYN, M. Avaliação de impacto ambiental de políticas públicas. Revista Internacional de Desenvolvimento Local, Campo Grande, v. 2, n. 3, p. 45-56. 2001.

PEREIRA, P. F. Conceito e implicaçóes dos espaços territoriais especialmente protegidos no ordenamento ambiental. Monografia (Especialização em Desenvolvimento Sustentável e Direito Ambiental). Centro de Desenvolvimento Sustentável. Universidade de Brasília, Brasília. 63 p. 2006. PEREIRA, P. F.; SCARDUA, F. P. Espaços territoriais especialmente protegidos: conceito e implicações jurídicas. Revista Ambiente \& Sociedade, São Paulo, v. 11, n. 1, Campinas, p. 81-97. 2008. 
PIOVESAN, A.; TEMPORINI, E.R. Pesquisa exploratória: procedimento metodológico para o estudo de fatores humanos no campo da saúde pública. Revista Saúde Pública, São Paulo, v. 29, n. 4 , p. 318-325.

PRADO FILHO, J. F. do; SOUZA, M. P. de. O licenciamento ambiental da mineração no Quadrilátero Ferrífero de Minas Gerais - uma análise da implementação de medidas de controle ambiental formuladas em EIAs/RIMAs. Engenharia Sanitária e Ambiental, Rio de Janeiro, v. 9, n. 4 , p. 343-349. 2004.

PRADO FILHO, J. F. O Processo de avaliação de impacto ambiental (AIA) de projetos e empreendimentos minerais como um instrumento de gestáo ambiental: estudo de casos no quadrilátero ferrífero (MG). Tese (Doutorado). Escola de Engenharia de São Carlos. Universidade de São Paulo, São Carlos. 258p. 2001.

RESOLUÇÃO CONAMA no 01, de 23 de janeiro de 1986. Disponível em: http://www.ibraop. org.br/site/media/legislacao/ambiental/resolucao_conama_001-86.pdf. Acesso: 11/07/11.

RESOLUÇÁO CONAMA no 03, de 28 de junho de 1990. Disponível em: http://www.ibram. df.gov.br/sites/400/406/00002049.pdf. Acesso:11/07/11.

RESOLUÇÁO CONAMA no 05, de 15 de junho de 1989. Disponível em: http://www.mma.gov. br. Acesso em: 09/10/2012.

RESOLUÇẤO CONAMA no 08, de 6 de dezembro de 1990. Disponível em: http://www.mma. gov.br. Acesso em: 09/10/2012.

RESOLUÇÃO CONAMA no 20, de 18 de junho de 1986. Disponível em: http://www.mma.gov. br/port/conama/res/res86/res2086.html. Acesso em: 11/07/11.

RESOLUÇÁO CONAMA no 357, de 17 de março de 2005. Disponível em: http://www.mma. gov.br. Acesso em: 11/07/11.

RESOLUÇÁO CONAMA no 436, de 22 de dezembro de 2011. Disponível em: http://www.mma. gov.br. Acesso em: 09/10/2012.

RIBEIRO, W. C. Geografia política e gestão internacional dos recursos naturais. Estudos Avançados, São Paulo, v. 24, n. 68, p. 69-80. 2010.

ROCHA, L.G.M. da.; DRUMMOND, J.A.; GANEM, R.S. Parques Nacionais Brasileiros: problemas fundiários e alternativas para a sua resolução. Revista de Sociologia e Política, Curitiba, v. 18, n. 36, p. 205-226. 2010. 
Breve análise dos instrumentos da política de gestão ambiental brasileira| Dalmo Arantes Barros - Luís Antônio Coimbra Borges Gleisson de Oliveira Nascimento - José Aldo Alves Pereira - José Luiz Pereira de Rezende - Rossi Alan Silva

RODRIGUES, M.M. Política Nacional do Meio Ambiente e a eficácia de seus instrumentos. In: Ambito Jurídico, Rio Grande, 74, (2010). Disponível em: http://www.ambito-juridico.com.br/ pdfsGerados/artigos/7500.pdf. Acesso: 04/07/2011.

ROSSI, A. A garantia da prestação de informaçóes relativas ao ambiente como instrumento de gestáo e de política ambiental no Brasil. Tese (Doutorado). Escola de Engenharia de São Carlos. Universidade de São Paulo, São Carlos. 147p. 2009.

SAMPAIO, R. S. da R. Direito Ambiental. Fundação Getúlio Vargas, v. 2, 43 p. 2008.

SÁNCHES, L. E. Avaliação de impacto ambiental: conceitos e métodos. São Paulo: Oficina de Textos. 495 p. 2008.

SCARDUA, F. P. Governabilidade e descentralizaçáo da gestáo ambiental no Brasil. Tese (Doutorado). Centro de Desenvolvimento Sustentável. Universidade de Brasília, Brasília. 238p. 2003.

SOUZA, A.R de. A efetividade das normas constitucionais programáticas. Revista da Faculdade de Direito de Campos, Campos dos Goytacazes, ano VI, n. 6, p. 9-44. 2005.

TOMIYAMA, S. Critérios para identificação dos princípios de direito ambiental. Tese (Doutorado). Direitos Difusos e Coletivos. Pontifícia Universidade Católica de São Paulo, São Paulo. 334p. 2009.

USEPA - UNITED STATES ENVIRONMENTAL PROTECTION AGENCY. Technical support document for water quality-based toxics control. 1991. Disponível em: http://www.epa. gov/npdes/pubs/owm0264.pdf. Acesso: 12 junho de 2011.

VARELA, C. A. Instrumentos de políticas ambientais, casos de aplicaçáo e seus impactos para as empresas e a sociedade. In: IX Encontro nacional sobre gestão empresarial e meio ambiente, Curitiba, 15 p. 2007.

VIEIRA, I.C.G.; BECKER, B.K. A revisão do Código Florestal e o desenvolvimento do país. Revista Ciência Hoje, Rio de Janeiro, v. 46, n. 274, p. 64-67. 2010.

Recebido em: 23/02/2012. Aprovado em: 3/10/2012. 


\section{Brief analysis of policy instruments of brazilian environmental management}

\section{Abstract}

This study describes the main Brazilian environmental policy instruments, discussing the main points that facilitate or hamper their effectiveness. For this, we carried search out a qualitative exploratory. The main flaw of the effectiveness of these instruments of environmental policy in Brazil is the lack of a clear understanding of the environmental policy, of its benefits and results in differents levels of environmental management. For the effectiveness of environmental legislation, through the use of instruments of the National Environmental Policy, is needed more than just a process of standardization of command and control. Other public policies are essential, as awareness of educational policies with investments in aspects related to sustainability, to changing consumer habits and lifestyle.

Keywords: Managements tools, environmental policy, effectiveness. 